\title{
Application of Prefabricated Vertical Drains in Soft Clay Improvement
}

\author{
Mahmoud S. Hammad, Ayman L. Fayed, Yasser M. El-Mossallamy
}

\begin{abstract}
A numerical study is performed to investigate the behavior of embankments built on soft soil deposits improved by the combination of preloading and prefabricated vertical drains. The study utilizes the three-dimensional finite element technique for the back analysis of two embankments in the Changi East reclamation project in Singapore. Different constitutive models are considered and yielded that the soft soil creep model (SSC) is most appropriate to model the behavior of the soft clay deposits. A parametric study is performed to investigate the various factors affecting the required improvement duration and the anticipated residual settlement. The study results show the significant influence of the variation of the PVDs length ratio (PVD depth to soft layer thickness) and spacing on both the duration of the consolidation process and the residual settlement while the PVDs configuration is found to be of minimal importance.
\end{abstract}

Index Terms-Soft clay, Soil improvement, Preloading, Prefabricated vertical drains.

\section{INTRODUCTION}

Dealing with soft soil formations imposes various geotechnical challenges. Excessive time-dependent settlement and low shear strength are the main characteristics of soft soil; hence, improving such deposits is essential to accommodate buildings and infrastructures safely. The technique of preloading is one of the most applied soil improvement techniques due to its simplicity, reliability, as well as its economic efficiency. It involves the application of a load equal to or higher than the load of the required structure before its construction. The applied load, usually an earth fill, causes pre-consolidation of the soft soil deposits, thus, reducing the post-construction settlement of the structures, in addition to increasing the shear strength parameters of the soft soil deposits. After the required degree of consolidation is achieved, the load is removed, entirely or partially, before commencing the construction activities.

The main shortcoming of the conventional preloading technique is the considerably long time required to achieve the target degree of consolidation due to the low permeability of the soft clay formations. In order to overcome such disadvantage, Vertical drains can be utilized to provide additional paths for the excess pore water pressure to dissipate via radial drainage, thus, accelerating the preloading process.

Mahmoud S. Hammad, Structural Department, Faculty of Engineering, Ain Shams University, Cairo, Egypt.

Ayman L. Fayed, Structural Department, Faculty of Engineering, Ain Shams University, Cairo, Egypt,

Yasser M. EI-Mossallamy, Structural Department, Faculty of Engineering / Ain Shams University, Cairo, Egypt.
Since the 1920s, many types and shapes of vertical drains were introduced. Sand drains constructed using conventional piling techniques were first utilized. Such drains were installed at a relatively large spacing to avoid disturbance of the soil. However, it was proven later that the efficiency of the vertical drainage system depends on the spacing between drains; thus, sand wicks were developed. A new era started in the 1970s as Akzo introduced the first synthetic band drain [1]. Since then, many prefabricated band type drains have been developed under various commercial names. PVDs were preferred over sand drains as they overcome some of the deficiencies of the sand drains. Rapid installation of prefabricated drains made it more economically efficient; also, the less disturbance caused by the installation of the PVDs in the surrounding soil layer yielded better performance and less time consumption during the preloading process.

The efficiency of numerical modeling in simulating the performance of the soil-PVD system has been proven through numerous published literature. However, the success of the numerical modeling is always governed by adequately choosing the appropriate constitutive model for the different considered elements, in addition to precisely simulating the actual construction stages and sequence. For soft clay formations, time-dependent constitutive models considering the creep effect are of great importance to simulate the soil behavior and improvement process. Three-dimensional finite element technique (software Plaxis 3D) adopting elastoplastic-creep behavior is utilized accordingly in the current research to simulate the improvement process of a published field case study in Singapore.

\section{CASE STUDY - CHANGI EAST RECLAMATION PROJECT}

\section{A. Location and description of the project}

The case study considered in this paper lies within the Changi East reclamation project located in the Republic of Singapore. The location and layout of the project are shown in Fig. 1. The original site is submerged underwater with a seabed elevation 5.5 meters below the sea level.

The case study consists of two adjacent embankments constructed within the northern area of the site; the main embankment under which vertical drains are installed, and the control embankment at which no vertical drains were used. The two embankments were constructed simultaneously with the same construction sequence and surcharge heights to be able to compare the behavior of both. 


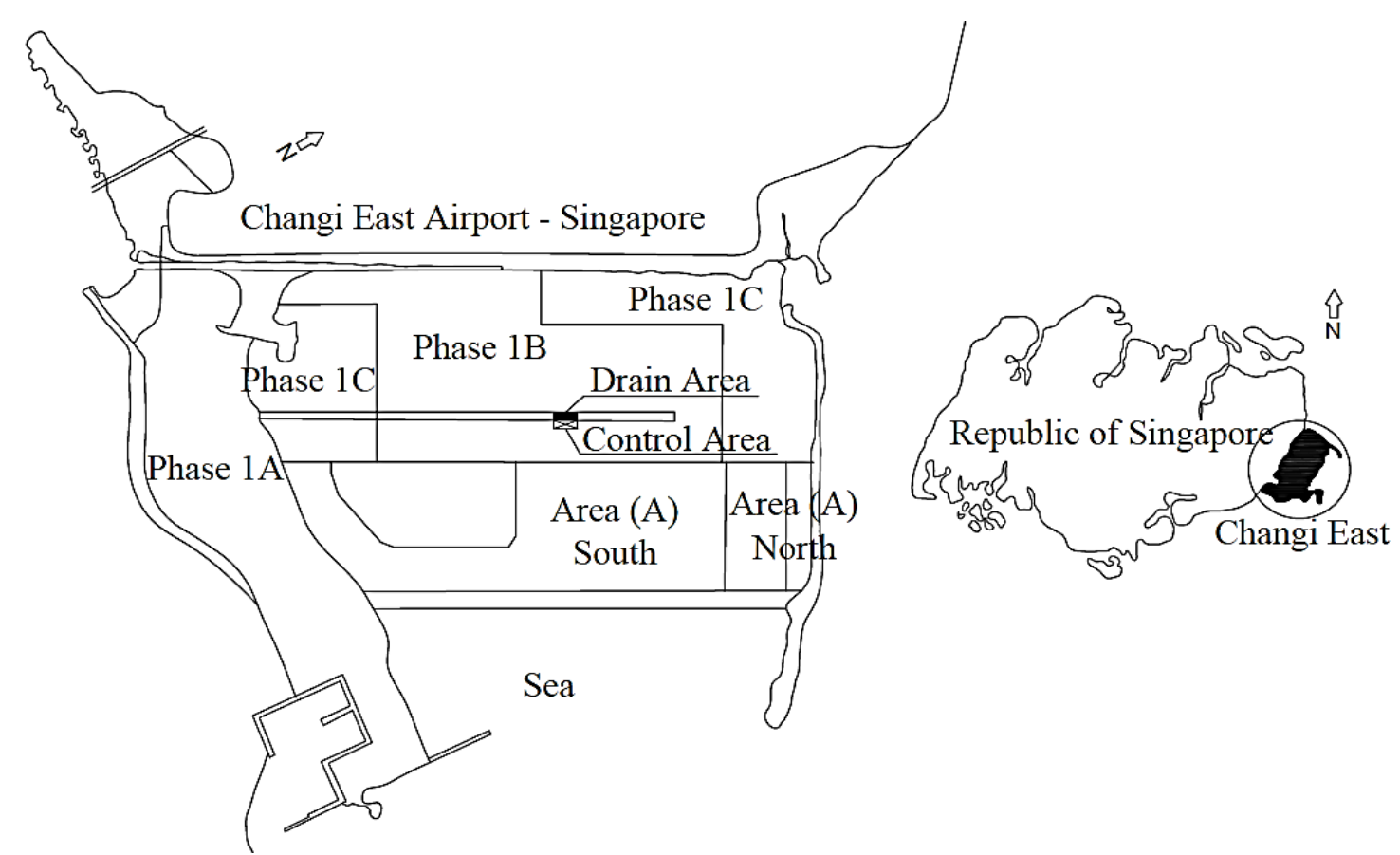

Fig. 1, Location and layout of Changi East [2]

\section{B. Soil characteristics at Changi East}

Based on extensive soil investigation works, the geotechnical conditions at Changi East indicated the presence of three distinct soil layers; upper marine clay layer with thickness of about 14 meters, followed by 2 meters of an intermediate stiff clay layer which is underlain by a lower marine clay layer that extends to about $35.5 \mathrm{~m}$ below sea water level. Finally, a Dense silty sand layer extends below the clayey layers [3]. Both the upper and lower marine clay layers can be considered as high to very high plastic silty clay layers; however, the upper clay layer was found to be more compressible than the lower clay layer. The soil parameters for the different soil layers stated shown in Table I.

The PVDs were installed in a square pattern with spacings of 1.5 meters in both directions. The properties of the installed drains are stated in Table II.

Table I- Soil parameters at Changi East [2], [3]

\begin{tabular}{|c|ccc|}
\hline Parameters & $\begin{array}{c}\text { Upper } \\
\text { Marine Clay }\end{array}$ & $\begin{array}{c}\text { Intermediate } \\
\text { Stiff Clay }\end{array}$ & $\begin{array}{c}\text { Lower } \\
\text { Marine Clay }\end{array}$ \\
\hline$\gamma_{\text {bulk }}\left(\mathrm{kN} / \mathrm{m}^{3}\right)$ & $14.23-15.7$ & $18.64-19.6$ & $15.7-16.67$ \\
$\mathrm{WC}(\%)$ & $70-88$ & $10-35$ & $40-60$ \\
$\mathrm{LL}(\%)$ & $80-95$ & 50 & $65-90$ \\
$\mathrm{PL}(\%)$ & $20-28$ & $18-20$ & $20-30$ \\
$\mathrm{e}_{\mathrm{o}}$ & $1.8-2.2$ & $0.7-0.9$ & $1.1-1.5$ \\
$\mathrm{G}_{\mathrm{s}}$ & $2.6-2.72$ & $2.68-2.76$ & $2.7-2.75$ \\
$\mathrm{c}_{\mathrm{c}}$ & $0.6-1.5$ & $0.2-0.3$ & $0.6-1.0$ \\
$\mathrm{c}_{\alpha}$ & $0.012-0.025$ & $0.0043-0.023$ & $0.012-0.023$ \\
$\mathrm{c}_{\mathrm{r}}$ & $0.09-0.16$ & $0.08-0.15$ & $0.14-0.2$ \\
$\mathrm{c}^{\prime}\left(\mathrm{kN} / \mathrm{m}^{2}\right)$ & 1 & 1 & 1 \\
$\varphi^{\prime}\left({ }^{\circ}\right)$ & 27 & 32 & 27 \\
$\mathrm{c}_{\mathrm{v}}\left(\mathrm{m}^{2} /\right.$ year $)$ & $0.47-0.6$ & $1-4.5$ & $0.8-1.5$ \\
$\mathrm{c}_{\mathrm{vr}}\left(\mathrm{m}^{2} /\right.$ year $)$ & $3-7$ & $10-30$ & $4-10$ \\
$\mathrm{c}_{\mathrm{h}}\left(\mathrm{m}^{2} /\right.$ year $)$ & $2-3$ & $5-10$ & $3-5$ \\
OCR & $1.5-2.5$ & $3-4$ & 2 \\
\hline \multicolumn{4}{c}{} \\
\hline
\end{tabular}

Table II, Specifications of installed PVDs [4]

\begin{tabular}{|c|c|c|c|c|}
\hline \multirow{2}{*}{\multicolumn{2}{|c|}{ Width Thick. }} & $\begin{array}{c}\text { Discharge capacity } \\
\text { (at } 350 \mathrm{kPa})\end{array}$ & \multirow{2}{*}{\multicolumn{2}{|c|}{ 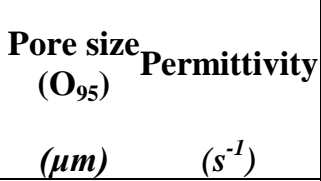 }} \\
\hline & $(\mathrm{mm})$ & $\begin{array}{c}\text { Straight Buckled } \\
\left(10^{-6} \mathrm{~m}^{3} / \mathrm{sec}\right)\end{array}$ & & \\
\hline 100 & $3-4$ & $>25 \quad>10$ & $<75$ & $>0.005$ \\
\hline
\end{tabular}

\section{Construction sequence}

Land reclamation works were commenced by the hydraulic placement of sand up to about $2.0 \mathrm{~m}$ above sea level; then, the vertical drains were installed. Soil instrumentations were placed directly before the installation of the PVDs in both the main and control embankments.

Reclamation sand was then used to apply the surcharge load by completing the construction of both embankments until a final height of $8.0 \mathrm{~m}$ above sea level is reached. The construction sequence of the embankments at the control and main embankments are shown in Fig. 2 and Fig. 3, respectively.

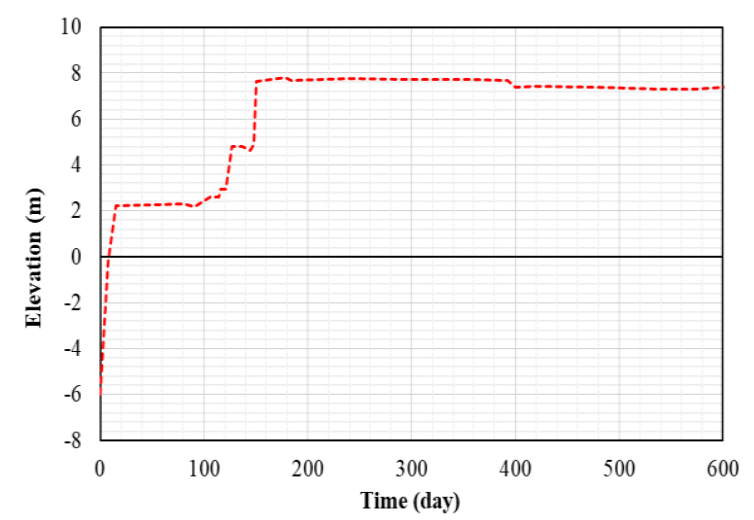

Fig. 2, Construction sequence for the control embankment [2] 


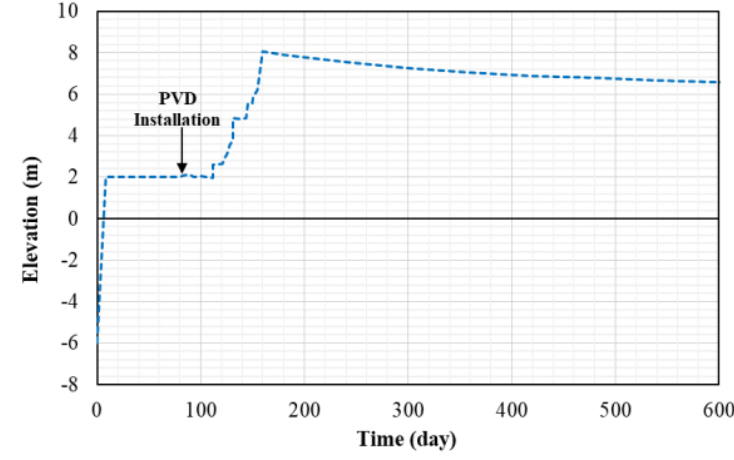

Fig. 3, Construction sequence for the main embankment [2]

\section{Instrumentation and field measurements}

Instrumentations were used to monitor the behavior of the two embankments, during and after applying the surcharge load. Surface settlement plates and deep settlement gauges were used to monitor the vertical deformation of soil at different depths. Also, Pneumatic, electric, and open type piezometers were used to measure the pore water pressure at various depths. The instrumentation layout at both the main embankment and the control embankment are shown in Fig. 9

The performed back analyses of the case study are based on the settlement readings measured at the surface plates (SP-04) and (SP-95) located under the control embankment and the main embankment at level (-5.50) meters respectively. The measurements shown in Fig. 4 were recorded for about 23 months after the PVD installation (about 26 months from the beginning).

Furthermore, the variation of the field settlement with depth at various times was measured using the deep settlement gauges and is shown in Fig. 5, and Fig. 6. Finally, as shown in Fig. 7 and Fig. 8, the excess pore water pressure was recorded at various depths below both embankments at levels Shown in Fig. 9.

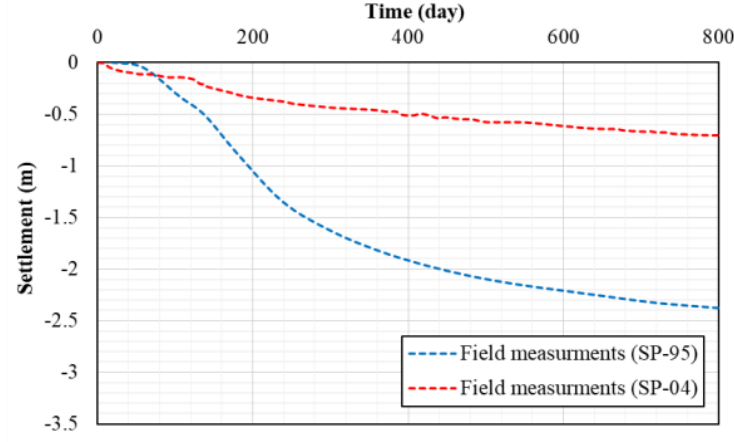

Fig. 4, Measurements for settlement under both embankment [2]

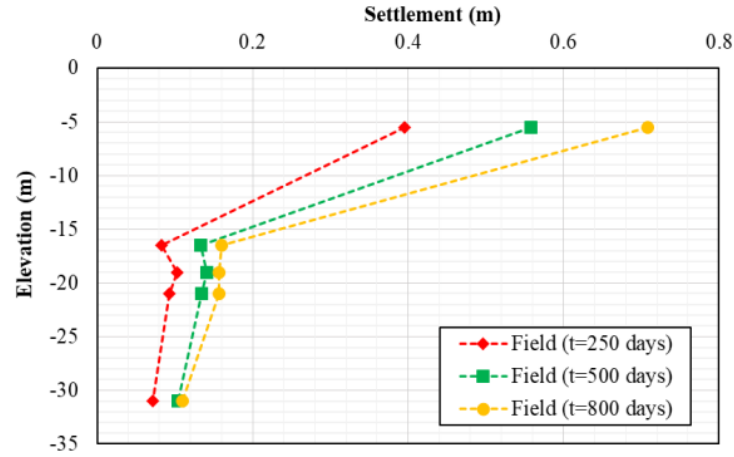

Fig. 5, Measurements of settlement at various depths under the control embankment [2]

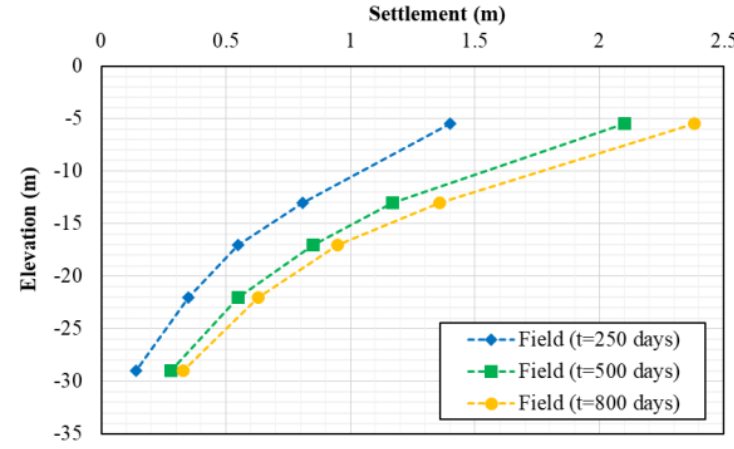

Fig. 6, measurements of settlement at various depths under the main embankment [2]

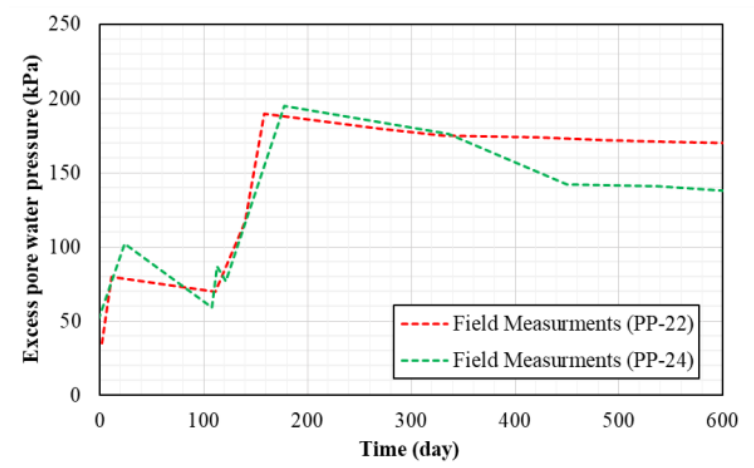

Fig. 7, Measurements for pore water pressure under control embankment [2]

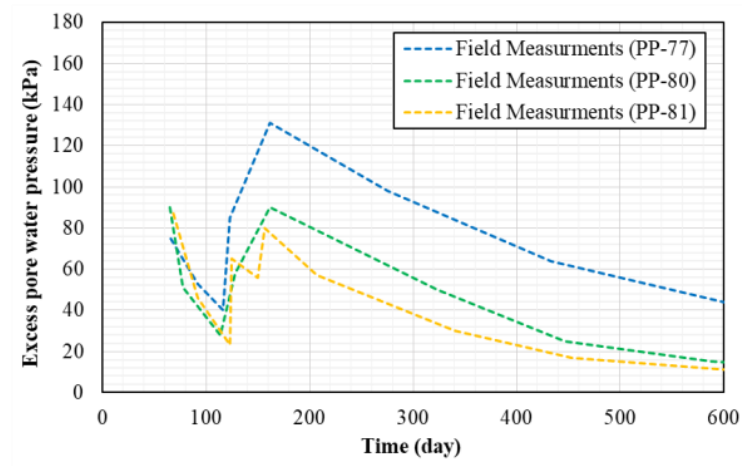

Fig. 8, Measurements of settlement at various depths under control embankment [2]

\section{BACK ANALYSIS OF THE CASE STUDY UTILIZING THE NUMERICAL MODELING}

The back analysis of the case study was performed using the three-dimensional finite element code, PLAXIS 3D 2018 Initially, back analysis of the control embankment was performed. As there were no drains installed at the control embankment, it was then considered as an ideal case that can be used to verify the chosen constitutive laws and soil parameters without considering the complex effects of the installation and buckling of the PVDs. After the verification of the suitable constitutive law, soil parameters, model geometry, and boundary conditions, back analysis of the main embankment was then carried out.

\section{A. Constitutive laws}

During the back analyses, the Soft soil creep (SSC) model was chosen to model the upper marine, intermediate stiff, and lower marine clay layers, respectively. SSC model is based on the Cam-clay model considering the secondary consolidation (creep performance of the soft clay). 


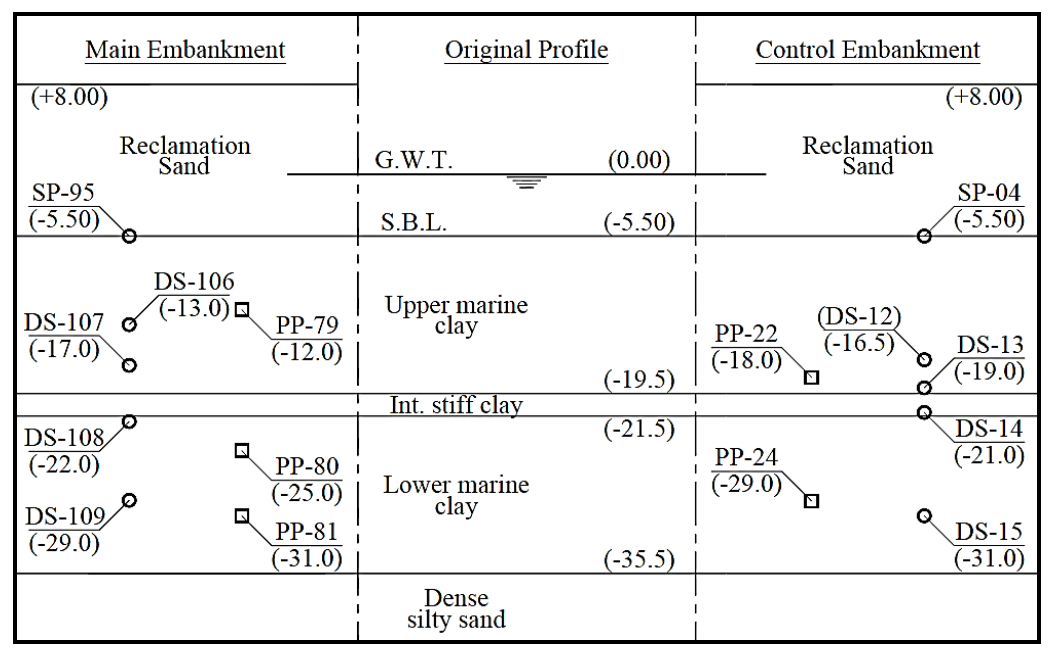

Fig. 9, Layout for in-situ test site instrumentation

The effective strength parameters in undrained conditions are used for the clay layers to allow estimating the increase in shear strength parameters with the consolidation progress. Furthermore, the reclamation sand was simulated using the Mohr-Coulomb (MC) model, in the drained condition.

\section{B. Geometry and boundary conditions}

Due to the vast extent of the embankment, modeling of the entire area was found to be time-consuming without significant technical gain. Thus, a portion of the embankments only was modeled and used to represent the entire embankment. In order to accurately compare the behavior of the control embankment and the main embankment, the extents of the models were unified. The lateral dimensions of the model are chosen to be 4.5 meters in both directions (X and $\mathrm{Y}$ ), to allow for the consideration of three columns and three rows of PVDs in the model. The vertical boundaries at $\mathrm{Y}=0, \mathrm{Y}=4.5, \mathrm{X}=0$, and $\mathrm{X}=4.5$ are axes of symmetry, thus, presenting the entire area of the embankment. The lower horizontal boundary of the model is chosen at the end of the lower marine clay layer at $\mathrm{Z}=-33.5 \mathrm{~m}$.

Boundary conditions for all the vertical borders are set by allowing for the vertical settlement while preventing the horizontal movement from taking place. Furthermore, the dissipation of the pore water through all the vertical boundaries is prohibited. However, for the lower horizontal boundary of the model, both the vertical and horizontal movements are prevented, while the dissipation of the pore water is allowed in order to consider the presence of the relatively higher permeable layer of dense silty sand below the lower marine clay. The form of the developed finite element models for both simulated cases are shown in Fig. 10, and Fig. 11.

\section{Construction sequence}

Through numerical modeling, an idealized construction sequence is adopted. A comparison between the actual and idealized construction sequences for both the control and main embankments are shown in Fig. 12, and Fig. 13 respectively.

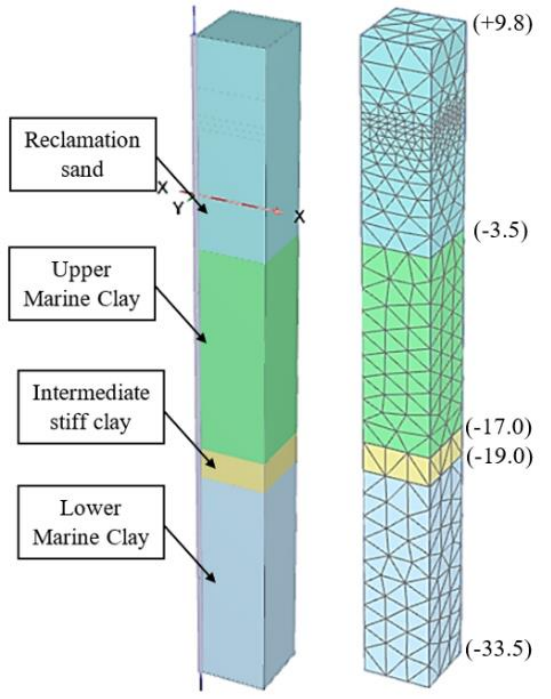

Fig. 10, Developed FE Mesh for the control embankment

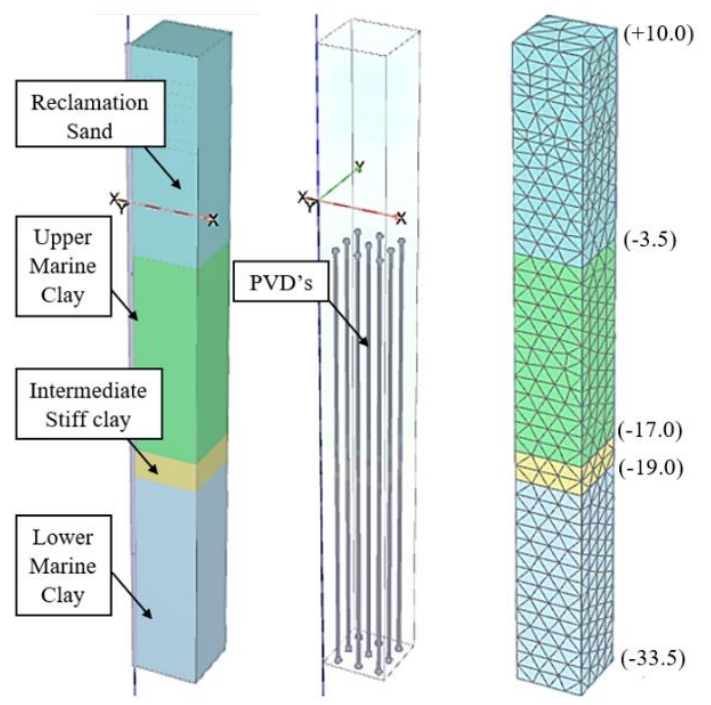

Fig. 11, Developed FE Mesh for the control embankment 


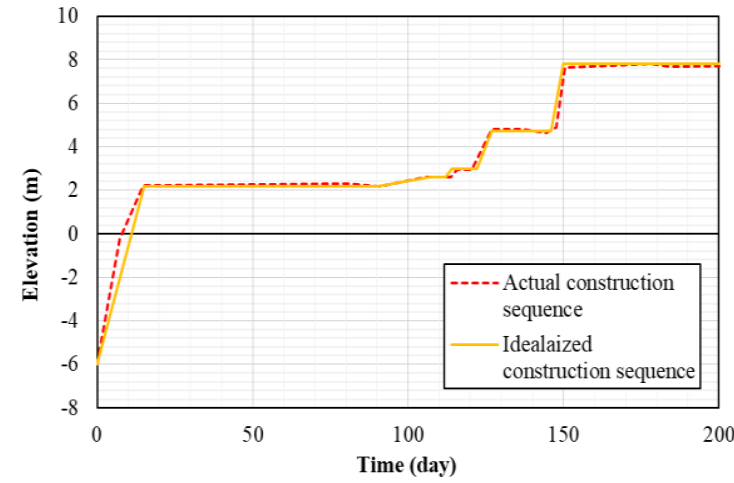

Fig. 12, Comparison between actual and idealized construction sequence for the control embankment

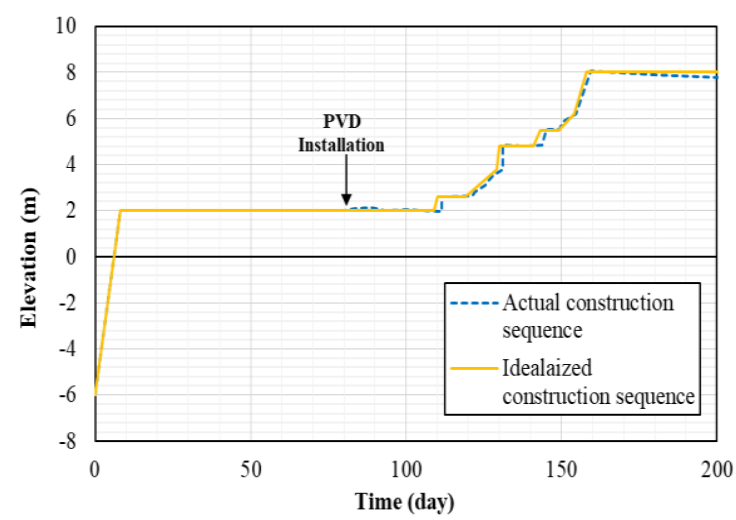

Fig. 13, Comparison between actual and idealized construction sequence for the main embankment

\section{Soil parameters and equivalent soil permeability}

The soil parameters adopted in the numerical modeling are based on the characteristics shown in Table I. Parameters used in the back analysis of the control embankment are presented in Table III. For the main embankment, most of the soil parameters shown in Table III are considered viable for the modeling of the main embankment. The differences in the soil parameters used for both models are limited to the permeability of the various soil layers due to the effect of the installation of the PVDs. Various factors such as the well resistance, the PVD buckling, and the smear effect are taken into consideration during modeling of the main embankment in order to simulate the actual behavior of the soil-vertical drains system as much as possible.

The well resistance varies with the variation of the permeability of the surrounding soil, length of the drains, and the drains discharge capacity. The reduction in the discharge capacity of the vertical drain due to well resistance can be evaluated using the well resistance factor (R). The well resistance could be considered as of negligible effect when the well resistance factor is greater than 5 [5]. Furthermore, the consolidation rate of the clay is generally not influenced by the discharge capacity of most of the commercially available PVD types especially those with significant length [6]. For the current case study, the length of the vertical drains is more than 30 meters, and the value for the resistance factor is significantly higher than 5 . Thus, the well resistance can be ignored during the numerical modeling of the studied case.

The reduction in the discharge capacity of the PVDs due to buckling of the drains varies significantly according to the shape and type of the drain deformation. However, the reduction was estimated to be in the range of $38 \%$ to $53 \%$ [1], [7].
Table III, Soil parameters used in the back analysis of the control embankment

\begin{tabular}{|c|c|c|c|c|}
\hline Parameters & $\begin{array}{c}\text { Upper } \\
\text { Clay }\end{array}$ & $\begin{array}{c}\text { Inter. Stiff } \\
\text { Clay }\end{array}$ & $\begin{array}{c}\text { Lower } \\
\text { Clay }\end{array}$ & $\begin{array}{l}\text { Rec. } \\
\text { Sand }\end{array}$ \\
\hline Constitutive & SSC & SSC & SSC & $\mathrm{MC}$ \\
\hline Drainage & Undrained & Undrained & Undrained & Drained \\
\hline$\gamma_{\text {unsat. }}\left(\mathrm{kN} / \mathrm{m}^{3}\right)$ & 15 & 19 & 15 & 17 \\
\hline$\gamma_{\text {sat. }}\left(\mathrm{kN} / \mathrm{m}^{3}\right)$ & 15.5 & 19.5 & 16 & 20 \\
\hline $\mathrm{k}_{\mathrm{x}}, \mathrm{k}_{\mathrm{y}}(\mathrm{m} / \mathrm{sec})$ & $10.2 \mathrm{E}-10$ & $13.8 \mathrm{E}-10$ & $9.96 \mathrm{E}-10$ & 1 \\
\hline $\mathrm{k}_{\mathrm{z}}(\mathrm{m} / \mathrm{sec})$ & $5.1 \mathrm{E}-10$ & $6.94 \mathrm{E}-10$ & $4.98 \mathrm{E}-10$ & 1 \\
\hline$c_{k}$ & 1.1 & 0.35 & 0.75 & $1 \mathrm{E} 15$ \\
\hline$c_{\text {ref }}^{\prime}\left(k N / m^{2}\right)$ & 1 & 1 & 1 & 1 \\
\hline$\varphi^{\prime}\left({ }^{\circ}\right)$ & 27 & 32 & 27 & 31 \\
\hline$\psi^{\prime}\left({ }^{\circ}\right)$ & 0 & 0 & 0 & 0 \\
\hline $\mathrm{e}_{\mathrm{o}}$ & 2.2 & 0.7 & 1.5 & 0.5 \\
\hline$\lambda^{*}$ & 0.095 & 0.077 & 0.104 & ------ \\
\hline$\kappa^{*}$ & 0.027 & 0.072 & 0.049 & ------- \\
\hline$\mu^{*}$ & $0.163 \mathrm{E}-2$ & $0.059 \mathrm{E}-2$ & $0.209 \mathrm{E}-2$ & ------ \\
\hline OCR & 2.5 & 3 & 2 & ------ \\
\hline $\mathrm{E}^{\prime}\left(\mathrm{kN} / \mathrm{m}^{2}\right)$ & & ------ & ------ & 13000 \\
\hline$E_{\text {oed }}\left(k N / m^{2}\right)$ & ------- & ------- & ------- & 17500 \\
\hline $\mathrm{G}\left(\mathrm{kN} / \mathrm{m}^{2}\right)$ & ------- & ------- & ------- & 5000 \\
\hline$v^{\prime}$ & ------- & ------- & ------- & 0.3 \\
\hline
\end{tabular}

Moreover, it was established by past scholars that the discharge capacity of the PVD does not affect the consolidation process. Thus, the use of vertical drain with infinite discharge capacity during numerical modeling is technically acceptable.

In order to consider the smear effect, the ideal solution is to model a smear zone surrounding each vertical drain. The soil parameters within the smear zone are identical to the undisturbed soil parameters except for the soil permeability which is reduced significantly. However, modeling a smear zone surrounding each vertical drain in the 3D FE model causes severe numerical errors while meshing due to the enormous increase in the number of generated elements and nodes. Accordingly, an equivalent soil parameter solution is adopted in which both the smeared and undisturbed soil clusters surrounding the PVDs are replaced by one equivalent soil layer [5]. The Equivalent soil shall have the same parameters of the undisturbed soil except for the equivalent permeability that is calculated according to:

$$
\mathrm{K}_{\mathrm{e}}=\frac{\mathrm{k}_{\mathrm{h}} \ln \left(\frac{\mathrm{r}_{\mathrm{e}}}{\mathrm{r}_{\mathrm{W}}}\right)}{\ln \left(\frac{\mathrm{r}_{\mathrm{e}}}{\mathrm{r}_{\mathrm{g}}}\right)+\frac{\mathrm{k}_{\mathrm{h}}}{\mathrm{k}_{\mathrm{a}}} \ln \left(\frac{\mathrm{r}_{\mathrm{g}}}{\mathrm{r}_{\mathrm{W}}}\right)}
$$

Where, $\left(r_{e}\right)$ is the radius of the influence zone, $\left(r_{w}\right)$ is the equivalent radius of the drain, $\left(r_{s}\right)$ is the radius of the smear zone, $\left(\mathrm{k}_{\mathrm{s}}\right)$ is the soil permeability within the smear zone, $\left(\mathrm{k}_{\mathrm{e}}\right)$ is the soil equivalent soil permeability.

For soft Bangkok clay, the diameter of the smear zone range between two and three times the equivalent cross-sectional area of the mandrel [8]. Furthermore, the permeability within the smear zone was found to be in the range of 0.33 to 0.5 of the undisturbed soil. Hence, the permeability of the equivalent soil used in numerical modeling shall be about $50 \%$ of the permeability of the undisturbed soil. The permeability used during the numerical modeling of the soft soil deposits before and after the installation of the PVDs in the main embankment is shown in Table IV. 
Table IV, Soil permeability used in the back analysis of the main embankment

\begin{tabular}{|c|cccc|}
\hline Soil Layer & \multicolumn{2}{|c|}{$\begin{array}{c}\text { Before PVD installation } \\
\text { (Smear not considered) }\end{array}$} & $\begin{array}{c}\text { After PVD } \\
\text { installation } \\
(\text { considering Smear) }\end{array}$ \\
& $\begin{array}{c}\boldsymbol{k}_{\boldsymbol{x}}, \boldsymbol{k}_{\boldsymbol{y}} \\
(\boldsymbol{m} / \mathbf{s e c})\end{array}$ & $\boldsymbol{k}_{z}(\boldsymbol{m} / \mathbf{s e c})$ & $\begin{array}{c}\boldsymbol{k}_{\boldsymbol{x}}, \boldsymbol{k}_{\boldsymbol{y}} \\
(\boldsymbol{m} / \mathbf{s e c})\end{array}$ & $\boldsymbol{k}_{z}(\boldsymbol{m} / \mathbf{s e c})$ \\
\hline Upper clay & $10.2 \mathrm{E}-10$ & $5.10 \mathrm{E}-10$ & $5.10 \mathrm{E}-10$ & $2.55 \mathrm{E}-10$ \\
Inter. clay & $13.8 \mathrm{E}-10$ & $6.94 \mathrm{E}-10$ & $6.94 \mathrm{E}-10$ & $3.47 \mathrm{E}-10$ \\
Lower clay & $9.96 \mathrm{E}-10$ & $4.98 \mathrm{E}-10$ & $4.98 \mathrm{E}-10$ & $2.49 \mathrm{E}-10$ \\
\hline
\end{tabular}

\section{E. Verification of the numerical models}

The comparison between the field settlement readings at (SP-04) and the corresponding settlement results from the numerical model for the control embankment are shown in Fig. 14. The comparison shows good agreement between the 3D FE model results and the field measurements. The settlement predicted by the $3 \mathrm{D}$ FE model is found to be slightly higher than the actual settlement readings during the first 150 days, i.e., the construction period. This is because of the slight variations between the actual construction procedure and the construction sequence adopted during the numerical modeling. The maximum difference between the results is about $20 \%$ at 120 days, as the field settlement was about $16 \mathrm{~cm}$, while the numerical model predicts a settlement of $20 \mathrm{~cm}$. However, for the rest of the comparison period, the behavior of the numerical model is quite close to that of the field measurements, with both showing a settlement of about $71 \mathrm{~cm}$ at the 800-days mark.

Similarly, good agreement is found between the results of the numerical modeling of the main embankment and the field measurements taken at (SP-95), as shown in Fig. 15. The results of the numerical model are slightly higher than the field measurements until reaching the 400-days mark. This is also referred to as the slight alteration of the construction sequence used in the numerical modeling from the actual construction sequence. However, the maximum difference is about $10 \mathrm{~cm}$ at 200 days, which constitutes about $8 \%$ difference in the corresponding results. After 400 days, the results of the numerical model fit well with the field measurements until the end of the field readings at 800 days.

Furthermore, both numerical models were allowed to complete the consolidation process until almost full dissipation of the excess pore water pressure is achieved (i.e., the excess pore water pressure of about only $1 \mathrm{kPa}$ was reached). The final settlement calculated by the 3D FE models was about 3.05 meters. This agrees well with the final settlement calculated using both the Asaoka's and the hyperbolic methods, which predicted the final settlement for (SP-04) settlement plate to reach about 3 meters. A comparison between the final settlement as calculated by Arulrajah (2005) and the 3D FE model is shown in Table V.

Moreover, the variation of the settlement with depth under both embankments at different periods obtained from the field measurements and the results of the numerical modeling is shown in Fig. 16, and Fig. 17. The comparison shows a good agreement between the results of the numerical model and the field measurements for both embankments as the settlement values almost coincide, especially at 500-day and 800-day charts.

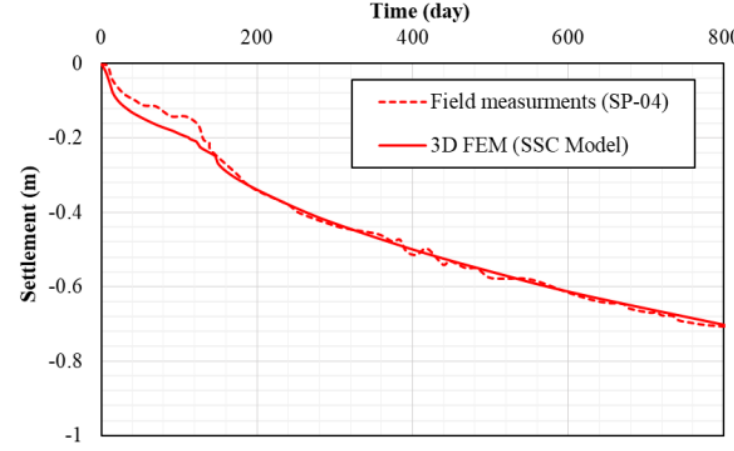

Fig. 14, Comparison between field measurements and SSC FEM results for settlement under the control embankment

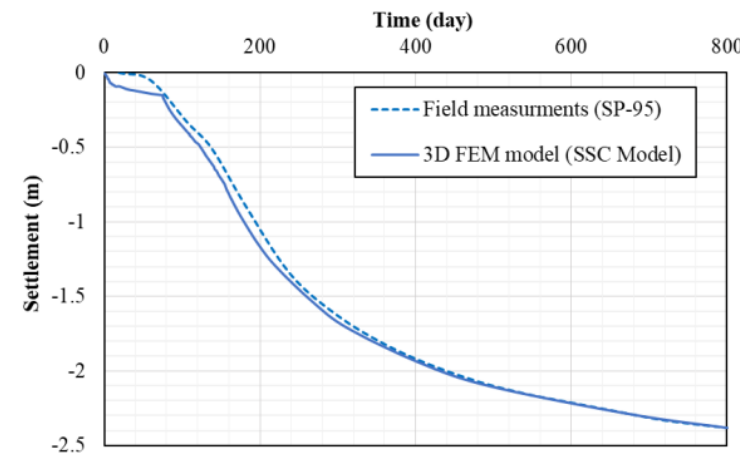

Fig. 15, Comparison between field measurements and SSC FEM results for settlement under the control embankment

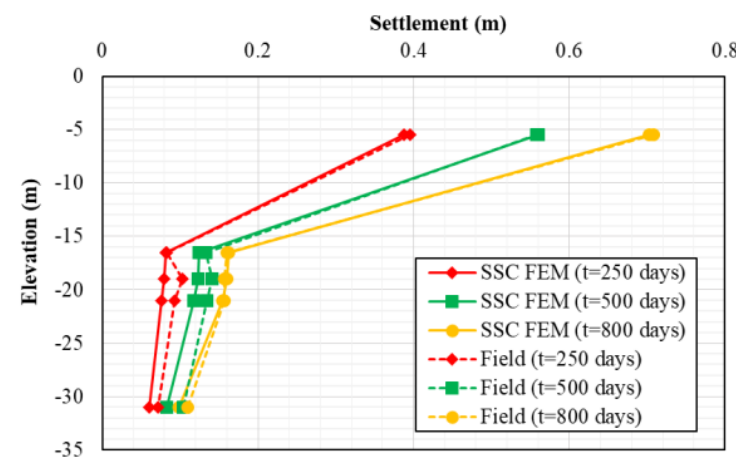

Fig. 16, Comparison between field measurements and SSC FEM results for settlement variation with depth under the control embankment

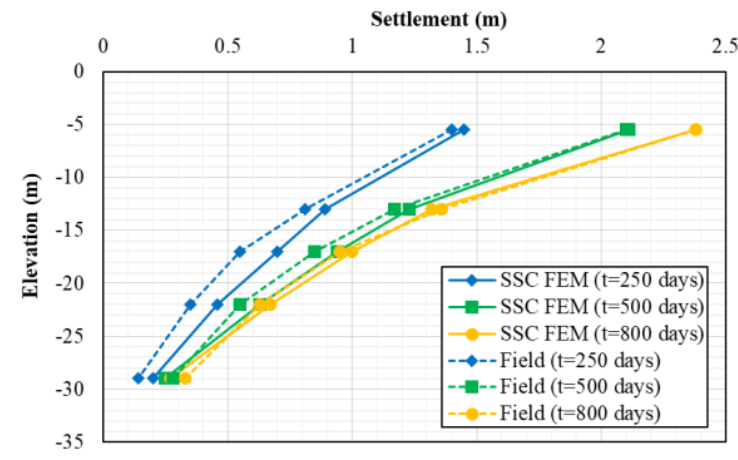

Fig. 17, Comparison between field measurements and SSC FEM results for settlement variation with depth under the main embankment 


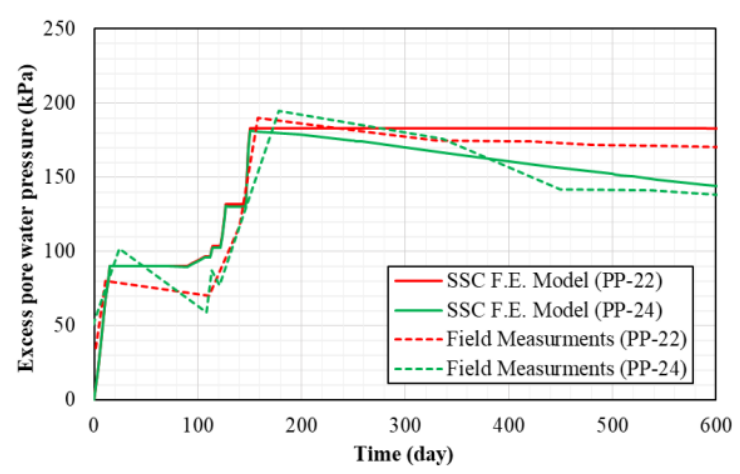

Fig. 18, Comparison between field measurements and SSC FEM results for excess PWP under the control embankment

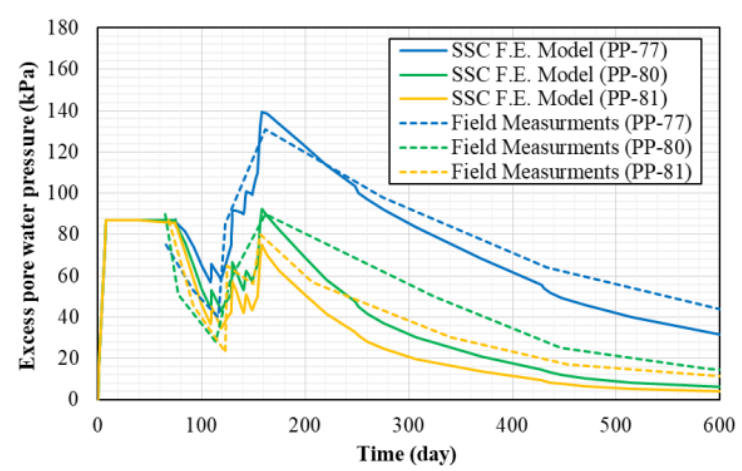

Fig. 19, Comparison between field measurements and SSC FEM results for excess PWP under the control embankment

Finally, a comparison of the excess pore water pressure between the values recorded at different piezometers and those yielded by the numerical model for both the control and main embankments is shown in Fig. 18 and Fig. 19. For the control embankment, the comparison shows a fair agreement between the numerical model results and the field measurements at both (PP-22) and (PP-24). Although the rate of dissipation of the excess pore water pressure in the numerical model is found to be slightly lower than the actual dissipation rate recorded at both (PP-22) and (PP-24), the difference between the numerical model and the field measurements did not exceed $10 \%$ at the end of the 800 -day mark. Furthermore, a good agreement is found at the main embankment between the results yielded by numerical modeling and the field measurements recorded at (PP-77), (PP-80) and (PP-81), respectively. The maximum excess pore pressure predicted by the FE model almost coincides with the field measurements at all piezometers.

Table V, Comparison between the predicted settlements from the numerical model and field measurements

\begin{tabular}{|c|c|c|}
\hline & [2] & SSC FEM \\
\hline Final settlement (m) & $3.0 / 3.05 *$ & 3.05 \\
\hline Settlement at 800 days $(\mathrm{m})$ & 0.708 & 0.702 \\
\hline$\stackrel{\mathrm{P}-04}{ }$ Degree of consolidation $(\%)$ & 23.6 & 23.0 \\
\hline $\begin{array}{cc}\text { Settlement at } 800 \text { days }(\mathrm{m}) \\
\underline{\mathrm{SP}-95} & \text { Degree of consolidation }(\%)\end{array}$ & $\begin{array}{l}2.38 \\
79.3\end{array}$ & $\begin{array}{c}2.38 \\
78\end{array}$ \\
\hline
\end{tabular}

a. 3/3.05: extrapolation of measurements to define the end settlement, first value using Asaoka's and the second value using the hyperbolic methods

\section{NUMERICAL MODELING USING DIFFERENT CONSTITUTIVE MODELS}

In the back analysis of the case study, the clay layers were modeled using the soft soil creep model (SSC), which considers the creep of the soil layers. To check the effect of creep, the case study is revisited using the soft soil (SS) model and the hardening soil (HS). The developed FE models utilizing these constitutive models respected the same geometry, boundary conditions and construction sequence of the verified SSC model. Moreover, the soil parameters used for the different soil layers in these models are identical to those used in the SSC model. The soil parameters used for the two models utilizing the SS model and the HS model are presented in Table VI and Table VII respectively, while the permeability is the same mentioned in Table IV.

As shown in Fig. 20, the results from the HS model for the control embankment are slightly higher throughout the investigated time frame. However, the difference between the HS model and the SSC model does not exceed $2 \%$. Furthermore, the SS model predicts higher settlement values than those calculated by the SSC model during the first 500 days. After that, the SSC model results exceeded the SS readings until the 800-days mark, with differences not exceeding $1 \%$ at any time. For the main embankment modeling results shown in Fig. 21, adopting the different three constitutive models, the settlements calculated by the SS model is higher than those yielded by the SSC model for the first 110 days (i.e., until the degree of consolidation reaches about $15 \%$ ). After that, the results of both models match until reaching 180 days, that is corresponding to a degree of consolidation of almost $33 \%$. Finally, the settlement predicted by the SS model becomes less than those of the SSC model, with the difference in results increasing as the consolidation degree reaches $100 \%$. Similarly, the results of the HS model are slightly higher than the SSC model in the short term, but after the consolidation degree reaching about $50 \%$ (at 270 days), the HS model yields lower settlement values than the SSC model.

Table VI, Soil parameters used in the FE model utilizing the soft soil model (SS)

\begin{tabular}{|c|c|c|c|c|}
\hline Parameters & $\begin{array}{c}\text { Upper } \\
\text { Clay }\end{array}$ & Inter. Clay & $\begin{array}{c}\text { Lower } \\
\text { Clay }\end{array}$ & Rec. Sand \\
\hline Model Type & $\mathrm{SS}$ & $\mathrm{SS}$ & $\mathrm{SS}$ & $\mathrm{MC}$ \\
\hline Drainage & Undrained & Undrained & Undrained & Drained \\
\hline$\gamma_{\text {unsat. }}\left(\mathrm{kN} / \mathrm{m}^{3}\right)$ & 15 & 19 & 15 & 17 \\
\hline$\gamma_{\text {sat. }}\left(\mathrm{kN} / \mathrm{m}^{3}\right)$ & 15.5 & 19.5 & 16 & 20 \\
\hline $\mathrm{c}_{\mathrm{k}}$ & 1.1 & 0.35 & 0.75 & $1 \times 10^{15}$ \\
\hline$c_{\text {ref }}^{\prime}(k N)$ & 1 & 1 & 1 & 1 \\
\hline$\varphi^{\prime}\left(^{\mathrm{o}}\right)$ & 27 & 32 & 27 & 31 \\
\hline$\psi^{\prime}\left(^{\mathrm{o}}\right)$ & 0 & 0 & 0 & 0 \\
\hline $\mathrm{e}_{\mathrm{o}}$ & 2.2 & 0.7 & 1.5 & 0.5 \\
\hline$\lambda^{*}$ & 0.095 & 0.077 & 0.104 & ------- \\
\hline$\kappa^{*}$ & 0.027 & 0.072 & 0.049 & ------- \\
\hline OCR & 2.5 & 3 & 2 & ------- \\
\hline $\mathrm{E}^{\prime}\left(\mathrm{kN} / \mathrm{m}^{2}\right)$ & ------- & ------- & ------- & 13000 \\
\hline $\mathrm{E}_{\mathrm{oed}}\left(\mathrm{kN} / \mathrm{m}^{2}\right)$ & ------- & ------- & ------- & 17500 \\
\hline $\mathrm{G}\left(\mathrm{kN} / \mathrm{m}^{2}\right)$ & ------- & ------- & ------- & 5000 \\
\hline$v^{\prime}$ & ------- & ------- & ------- & 0.3 \\
\hline
\end{tabular}


Table VII, Soil parameters used in the FE model utilizing the Hardening soil model (HS)

\begin{tabular}{|c|c|c|c|c|}
\hline Parameters & $\begin{array}{l}\text { Upper } \\
\text { Clay }\end{array}$ & Inter. Clay & $\begin{array}{l}\text { Lower } \\
\text { Clay }\end{array}$ & $\begin{array}{l}\text { Rec. } \\
\text { Sand }\end{array}$ \\
\hline Model Type & HS & HS & $\mathrm{HS}$ & $\mathrm{MC}$ \\
\hline Drainage & Undrained & Undrained & Undrained & Drained \\
\hline$\gamma_{\text {unsat. }}\left(\mathrm{kN} / \mathrm{m}^{3}\right)$ & 15 & 19 & 15 & 17 \\
\hline$\gamma_{\text {sat. }}\left(\mathrm{kN} / \mathrm{m}^{3}\right)$ & 15.5 & 19.5 & 16 & 20 \\
\hline $\mathrm{c}_{\mathrm{k}}$ & 1.1 & 0.35 & 0.75 & $1 \times 10^{15}$ \\
\hline $\mathrm{c}_{\text {ref }}^{\prime}(\mathrm{kN})$ & 1 & 1 & 1 & 1 \\
\hline$\varphi^{\prime}\left({ }^{\circ}\right)$ & 27 & 32 & 27 & 31 \\
\hline$\psi^{\prime}\left(^{o}\right)$ & 0 & 0 & 0 & 0 \\
\hline $\mathrm{e}_{\mathrm{o}}$ & 2.2 & 0.7 & 1.5 & 0.5 \\
\hline $\mathrm{E}_{50}\left(\mathrm{kN} / \mathrm{m}^{2}\right)$ & 1320 & 1630 & 1200 & ------- \\
\hline $\mathrm{E}_{\mathrm{oed}}\left(\mathrm{kN} / \mathrm{m}^{2}\right)$ & 1050 & 1030 & 960 & ----- \\
\hline $\mathrm{E}_{\mathrm{ur}}\left(\mathrm{kN} / \mathrm{m}^{2}\right)$ & 6630 & 3260 & 3700 & ---- \\
\hline OCR & 2.5 & 3 & 2 & ------- \\
\hline $\mathrm{E}^{\prime}\left(\mathrm{kN} / \mathrm{m}^{2}\right)$ & ------- & ------ & ------- & 13000 \\
\hline$E_{\text {oed }}\left(\mathrm{kN} / \mathrm{m}^{2}\right)$ & ------- & ------- & ------- & 17500 \\
\hline $\mathrm{G}\left(\mathrm{kN} / \mathrm{m}^{2}\right)$ & ------- & ------- & ------- & 5000 \\
\hline$v^{\prime}$ & ------- & ------- & ------- & 0.3 \\
\hline
\end{tabular}

Generally, both the hardening soil (HS) and soft soil (SS) models show good agreement with the soft soil creep (SSC) model and the field measurements for the relatively short-term period after the preloading process starts. However, as the degree of consolidation reaches about 30-50 $\%$, the two models predict less settlement values, which could be referred to the ignorance of both models to the creep of the soft clay layers, thus estimating less deformations than the actual behavior of this soft soil formation. Moreover, the difference in the predicted settlement between the SSC model and both the SS and HS models depends mainly on the creep behavior of the soil deposit, as it becomes more significant for the soil deposits with a higher coefficient of secondary consolidation.

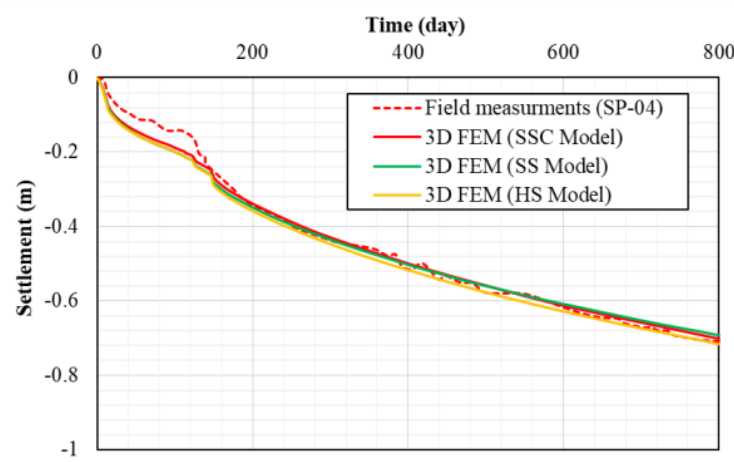

Fig. 20, Comparison between field measurements and SSC,

SS, HS 3D FEM under the control embankment

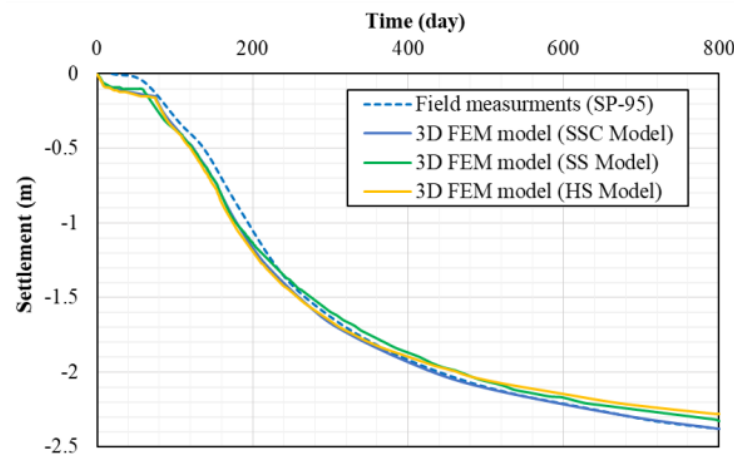

Fig. 21, Comparison between field measurements and SSC, SS, HS 3D FEM under the control embankment

\section{PARAMETRIC STUDY}

Since the use of vertical drains does not decrease the final settlement of the soft soil deposits, the functionality of using vertical drains can only be measured by its ability to accelerate the consolidation process and hence reduce the required preloading duration. However, the reduction in time depends on various factors such as the spacing between the vertical drains, length of the drains, the pattern of drain configuration, and the thickness of the soft soil deposit.

A parametric study is performed to investigate the effects of the variation of PVD spacing and length on the reduction in time of the preloading process while taking different PVD configurations and different depths of the PVD related to the thicknesses of the soft soil layers into consideration. The reduction in time is presented by the time factor (TF), which is defined as the ratio between the time required to achieve a $90 \%$ degree of consolidation for both cases with and without vertical drains, respectively. The time factor can be calculated using:

$$
T F=\frac{t_{90 \%, \text { with } P V D}}{t_{90 \% \text {. without } P V D}}
$$

Furthermore, the effect of the previously mentioned parameters on the post-operative long- term settlement is investigated. The study proposed a period of 5 months to complete the construction of the embankment, i.e. same as the original case study, after which a delay period of 9 months is adopted to allow for consolidation to take place, this is followed by the application of $20 \mathrm{kPa}$ distributed load as the operation load for the runway embankment. The improvement in the post-operative long-term settlement is investigated by the introduced settlement factor (SF) which is the ratio between the settlement at 50 years operation time for both cases with and without vertical drains respectively as shown:

$S F=\frac{S_{50 \text { years, with PVD }}}{S_{50 \text { vears,without PVD }}}$

The settlement considered in the SF ratio is the rest settlement after applying the $20 \mathrm{kPa}$ operation load as this rest settlement will affect the road pavement serviceability.

The parametric study was performed based on the verified FE model of the case study and using the same soil parameters, constitutive laws, and boundary conditions.

\section{A. Effect of drain spacing}

The effect of vertical drain spacing is investigated by varying the ratio between the drain spacing and the thickness of the soft soil layer. Two different thicknesses for the soft soil deposit are adopted $(16 \mathrm{~m}$ and $30 \mathrm{~m})$, while the PVD was chosen to penetrate the entire soft soil layer in all cases.

The study is performed using both the triangular and the square installation patterns for the drains. Although the boundary conditions and the soil parameters are the same as the original case study, the dimensions of the model are changed with the change of the pattern, the spacing, and the thickness of the soft soil layer. 
As shown in Fig. 22, the increase in the spacing between the vertical drains causes an increase in the time factor. Hence, a longer time is required to achieve a $90 \%$ consolidation degree. As the time factor reaches 1, the effect of PVDs becomes insignificant. This value is reached at a spacing to length ratio of about 0.5 and 0.35 for the soft soil layer of thickness 30 meters and 16 meters, respectively. Furthermore, the effect of the vertical drains in reducing the consolidation time decreases as the thickness of the soft soil layer decreases.

Also, the increase in the PVD spacing causes an increase of the settlement factor, i.e., increase in post-operative long-term settlement, until a spacing to thickness ratio of about 0.3 and 0.35 is reached for the soft soil layer of thickness 30 meters and 16 meters respectively, at which the effect of the PVDs is insignificant. Furthermore, as the PVD spacing increases beyond the previously mentioned ratio, the long-term settlement decreases again, which can return to the reduction in the achieved degrees of consolidation by the end of the assumed operation time of 50 years as the spacing between PVDs increases.

Finally, although the triangular pattern is found to have a slightly better effect on the reduction of both the consolidation time and the long-term settlement than the square pattern, the difference between both patterns is found to be of a minimal effect as the two curves are very close to each other.

\section{B. Effect of drain length to the soft layer thickness}

The performance of the floating PVDs is studied by investigating the effect of the drain length on both the time factor and the settlement factor. Through the study, the spacing between the drains are kept at 1.5 meters, and the boundary conditions and soil parameters were also maintained the same as the original case study. Like the previous analyses, the effect of the PVD length is investigated for both the rectangular and square patterns of the PVDs. Also, the study utilized both 30 meters and 16 meters as thicknesses for the soft soil layer.

From the performed analyses, the time factor was found to be very sensitive to the variation in the length of the PVD, especially at the small PVD length to soil thickness ratios. However, after the ratio between the PVD length to the soil thickness reaches a value of about 0.65 , the effect of increasing the PVD length becomes almost insignificant. This can be referred to as the fact that most of the settlement of the soft soil layer occurs at the upper part of the layer, which is profoundly affected by the fact that the soil stiffness of normally consolidated clay increases with depth. This can also be noticed as the reduction in consolidation time decreases as the thickness of the soft soil layer decreases.

Similarly, as the PVD length increases, the reduction in long-term settlement increases until a PVD length to soft soil thickness ratio of about 0.9 is reached, after which the effect of increasing the PVD length is insignificant. Also, the reduction in long-term settlement reduces as the layer thickness decreases.

Furthermore, the carried-out study proved that there is no significant difference between triangular and square patterns.

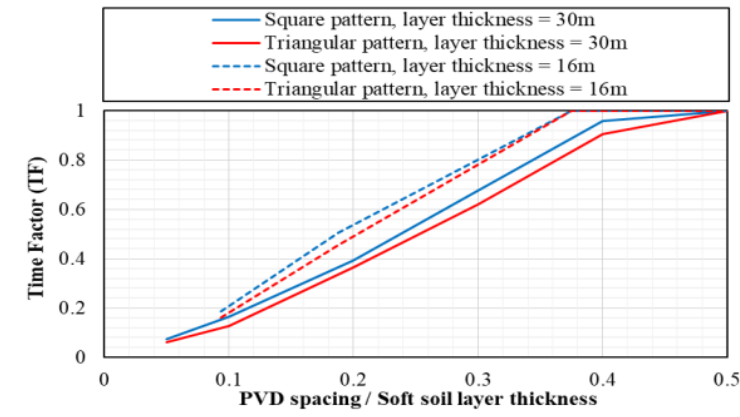

Fig. 22, Effect of PVD spacing on the time factor

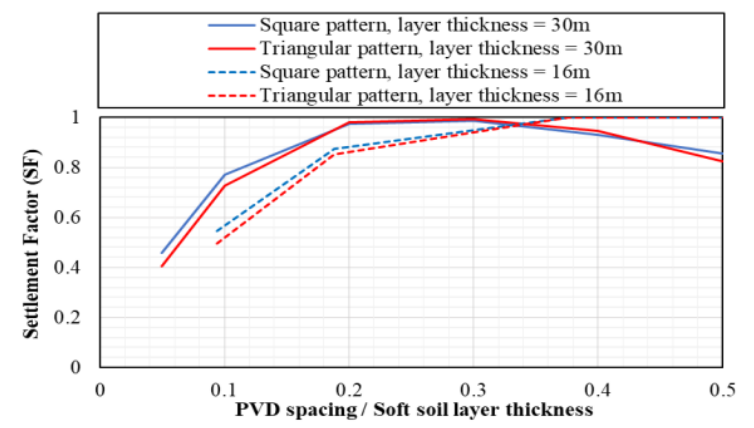

Fig. 23, Effect of PVD spacing on the settlement factor

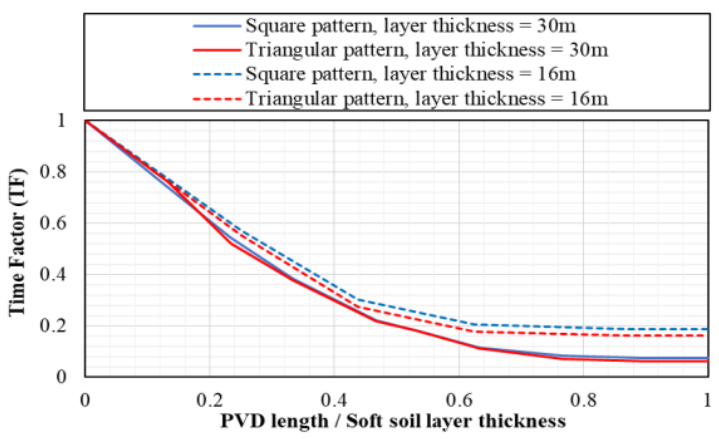

Fig. 24, Effect of PVD length on the time factor

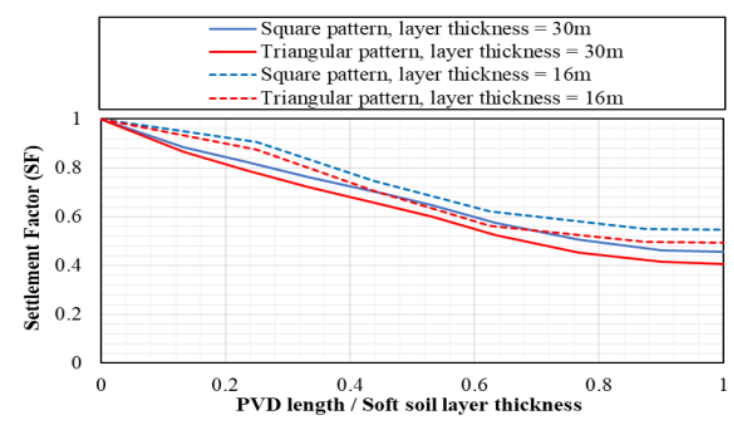

Fig. 25, Effect of PVD length on the settlement factor

\section{SUMMARY AND CONCLUSIONS}

In this study, numerical analyses were performed to investigate the behavior of embankments built on soft soil deposits improved by the preloading process, accompanied by the use of prefabricated vertical drains. Three-dimensional finite element code PLAXIS 3D 2019 was used in the back analyses of embankments in the Changi East reclamation project in Singapore with and without PVD. Using the soft soil creep model (SSC) for simulating the soft soil deposits resulted in good agreement between the predicted and measured settlement values.

On the other hand, utilizing the soft soil model (SS) and hardening soil model (HS) in the numerical modeling resulted 
in less predicted settlement values compared to the field measurements and the predicted values using the (SSC) model, as they do not take the secondary consolidation into account. Nevertheless, the difference between the results with or without considering creep is not highly significant in the studied case. This is due to the small contribution of creep in the studied case. Ignoring the creep effect, the results applying either the soft soil or the hardening soil models are comparable to each other.

A parametric study was performed to investigate the various factors affecting the time performance applying PVD. The performed analyses showed that the consolidation process is sensitive to the variation of both the PVDs length and spacing, while the pattern of the PVDs (square versus triangular) was found to be of minimal effect. The following conclusions were drawn out from the performed study:

- Three-dimensional finite element modeling can accurately depict the behavior of embankments built over soft soil deposits improved by Preloading accompanied by prefabricated vertical drains.

- The smearing effect can be considered by applying the equation developed by Lin et al. (2000).

- Generally, both the soft soil and the hardening soil models are appropriate to simulate the performance of PVD in soft clay in the case where creep has a minor contribution. In cases where creep can play an important role, soft soil with creep should be applied.

- Increasing the spacing between the drains increases the time required to accomplish the consolidation process. The effect of the PVDs becomes insignificant when their spacing to soft soil layer depth ratio reaches a specific value. This value depends on the thickness of the soft soil layer. Generally, the consolidation time can be reduced significantly as the length of the PVDs to the thickness of the soft soil ratio increases up to about 0.6 to 0.7 . After this reaching this ratio, the effect of increasing the PVD length becomes insignificant. Furthermore, the achieved reduction in consolidation time depends on the thickness of the soft soil layer as the reduction in time decreases with the reduction in the thickness of the soft soil deposit. This is due to the increase in the stiffness of normally consolidated clay with depth.

- Also, the settlement factor reduces significantly with the increase of the drain length to the soft layer thickness until this ratio reaches a value of 0.8 to 0.9 , after which the increase of the PVD length has no significant effect. The reduction in long-term settlement reduces as the layer thickness decreases.

- The pattern of installation of the vertical drains (square versus triangular) is found to be of minor effect on the soft clay improvement process.

\section{REFERENCES}

[1] I. Sathananthan, "Modelling of vertical drains with smear installed in soft clay," $P h D$, p. 305, 2005.

[2] A. Arulrajah, "Field measurements and back-analysis of marine clay geotechnical characteristics under reclamation fills," Distribution, no. February, 2005.

[3] B. M. Win, A. Arulrajah, and V. Choa, "The hydraulic conductivity of Singapore Marine Clay at Changi," Q. J. Eng. Geol., vol. 31, no. 4 pt 4, pp. 291-299, 1998.

[4] J. Chu, M. W. Bo, and V. Choa, "Practical considerations for using vertical drains in soil improvement projects," Geotext. Geomembranes, vol. 22, no. 1-2, pp. 101-117, 2004.
[5] D. G. Lin, H. K. Kim, and A. S. Balasubramaniam, "Numerical modeling of prefabricated vertical drain," Geotech. Eng., vol. 31, no. 2, pp. 109-125, 2000.

[6] B. Indraratna, C. Rujikiatkamjorn, V. Wijeyakulasuriya, G. Mcintosh, and R. Kelly, "Soft soils improved by prefabricated vertical drains: performance and prediction," pp. 227-246, 2010.

[7] J. W. Dijkstra and R. M. Bodamer, "Determination of the discharge capacity of buckled PVD's," 10th Int. Conf. Geosynth. ICG 2014, pp. $1-8,2014$.

[8] D. T. Bergado, P. V Long, and A. S. Balasubramaniam, "Compressibility and flow parameters from PVD improved soft Bangkok clay,” Geotech. Eng., vol. 27, no. 1, pp. 1-20, 1996.

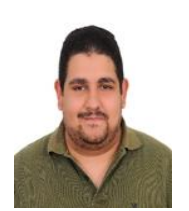

Eng. Mahmoud El Shawaf Hammad is working as a teaching assistant of geotechnical Engineering and foundations at Faculty of Engineering, Ain Shams University, Cairo, Egypt, since April 2009. B.Sc. of Structural Engineering from Ain Shams University (2008). M.Sc. in Geotechnical Engineering from Ain Shams University (2014). Member of the Egyptian Engineers Syndicate (since 2008). Eng. Mahmoud El Shawaf has over ten years of experience in numerous structural and geotechnical engineering projects as a designer and consultant. Research interests cover soil mechanics, rock mechanics, soil improvement, soil stabilization, soft soil behavior, deep foundations, the behavior of problematic soils, numerical modeling.

Contact information: Geotechnical Engineering and Foundations Laboratory, Faculty of Engineering, Ain Shams University, 1 El Sarayat st., El Waili, Postal code 11535, Cairo, Egypt.

Tel: +20-1006666502

Orchid ID: 0000-0002-1239-257X

Dr. Ayman Fayed has over 25 years of experience as an educator,

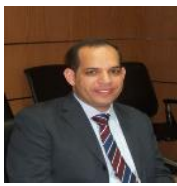
researcher, and consultant specializing in the areas of deep excavations, ground improvement, shallow and deep foundations, soil-structure interaction, and in-situ testing of soils. Dr. Fayed is an Associate Professor of geotechnical engineering at the faculty of engineering Ain Shams University that is one of the top universities in the middle east and Africa. Through his academic career, Dr. Fayed has authored or co-authored many publications in the geotechnical and foundation engineering field that were published in international journals and conferences. Dr. Fayed, as well, has supervised or co-supervised several M.Sc. and Ph.D. dissertations in geotechnical engineering. As an engineering consultant working at Dar Al-Hadassah consultants, which is one of the top engineering firms in the world, Dr. Fayed has participated in the design and management of large-scale geotechnical projects in different regions of the world especially in the middle east and Africa.

Contact information: Geotechnical Engineering and Foundations Laboratory, Faculty of Engineering, Ain Shams University, 1 El Sarayat st., El Waili, Postal code 11535, Cairo, Egypt.

Tel: +20-1006666502

Prof. Yasser El-Mossallamy has been a researcher and consultant for 34

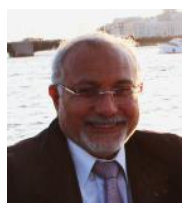
years. His work includes the application of numerical modeling and analyses in geotechnical projects. He has a vast experience with the design and construction of raft and piled raft foundations of high-rise buildings and bridge foundation. He was also involved in many projects dealing with special measures to increase the stability of landslides, soil improvement, rockfall hazards, and tunneling. Prof. El-Mossallamy has finished his Ph.D. in Germany and has worked by ARCADIS Consult in Germany for about 13 years. Prof. El-Mossallamy joints till now Arcadis in many projects worldwide (e.g., 3rd Istanbul Airport). Prof. Yasser has a broad experience in different countries such as Germany, China, Turkey, Egypt, Saudi Arabia, Kuwait and UAE, Jordanian. Prof. El-Mossallamy has a wide experience with Megaprojects dealing with the foundation of high-rise buildings, bridges, tunnels, dams, highways, railways, airports and silos.

Prof. El-Mossallamy is also a professor at Ain Shams University, Cairo, Egypt. Prof. El-Mossallamy has more than 100 publications dealing with different geotechnical topics.

Contact information: Geotechnical Engineering and Foundations Laboratory, Faculty of Engineering, Ain Shams University, 1 El Sarayat st., El Waili, Postal code 11535, Cairo, Egypt.

Tel: +20-1006666502 